\title{
CARDIOPULMONARY PHYSIOLOGICAL RESPONSES TO HEAVY EXERCISE IN PATIENTS WITH ANEMIA*
}

\author{
By BRIAN J. SPROULE, $\dagger$ JERE H. MITCHELL, $\ddagger$ AND WILLIAM F. MILLER
}

\author{
(From the Cardiopulmonary Laboratory, Department of Internal Medicine, The University of \\ Texas Southwestern Medical School, and Parkland Memorial Hospital, \\ Dallas, Texas)
}

(Submitted for publication June 22, 1959; accepted October 23, 1959)

The hemodynamic adaptation of the human body to acute and chronic anemia has been extensively studied. There are few reports, however, of investigations of the response of anemic individuals to exercise. The most exhaustive study to date is that of Bishop, Donald and Wade (1), who evaluated 11 patients with anemia at moderate levels of exercise, performed in a supine position at minute ventilations up to $20 \mathrm{~L}$.

Preliminary observations in our laboratory indicated that subjects suffering from moderately severe anemia are capable of exerting themselves on a treadmill at levels of exercise approaching or exceeding those producing maximal oxygen intake in normal subjects. This led us to investigate the response of anemic subjects to very severe exertion.

\section{MATERIALS AND METHODS}

Nine patients with anemia of various types comprised the case material for study. Table I summarizes the characteristics of these patients, as well as the level of exercise performed by each.

Exercise was performed on a treadmill, the grade and speed of which could be adjusted so that a maximal amount of oxygen was extracted from inspired air by the exercising subject (2).

Blood samples were drawn from the brachial artery, brachial vein, and femoral vein through plastic catheters, with the subject standing at rest and during the last minute of a 2.5 minute exercise period. The samples were analyzed for $\mathrm{O}_{2}$ and $\mathrm{CO}_{2}$ content, $\mathrm{O}_{2}$ capacity, $\mathrm{pCO}_{2}, \mathrm{pO}_{2}$, and $\mathrm{pH}(2)$. Oxygen and $\mathrm{CO}_{2}$ contents were determined by Van Slyke manometric analysis, $\mathrm{pCO}_{2}$ was calculated from the $\mathrm{CO}_{2}$ content, using the Singer-Hastings nomogram (3), oxygen tension was determined polarographically $(4,5)$ and $\mathrm{pH}$ was measured at $37^{\circ} \mathrm{C}$ with a Stand-

* This study was supported in part by funds from United States Public Health Service, Grant 2113, and the Dallas Heart Association.

$\dagger$ Present address : the University of Alberta, Edmonton, Canada.

\$ United States Public Health Service Trainee. Present address: National Heart Institute, Bethesda, Md. ard Cambridge micro-glass electrode and a Beckman model G-S pH meter. To confirm polarographic values, $\mathrm{pO}_{2}$ also was often measured by the micro-bubble equilibration technique (6).

Mean circulation time, cardiac output and "central blood volume" were calculated from dye dilution curves according to the method of Hamilton, Moore, Kinsman and Spurling (7). For this determination, $10 \mathrm{mg}$ of Evans blue (T1824) dye was delivered at the end of an 18 inch length of PE 90 (polyethylene) catheter into the axillary vein, and arterial blood was collected from the brachial artery through a 12 inch length of PE 90 catheter. Expired air was collected at rest and during the last minute of the exercise period, and the $\mathrm{O}_{2}$ and $\mathrm{CO}_{2}$ contents were determined on a Beckman E-2 $\mathrm{O}_{2}$ analyzer and a Listone-Becker infrared $\mathrm{CO}_{2}$ analyzer, respectively. Gas volumes were measured in a Tissot spirometer and were corrected to BTPS or STPD as indicated. Physiological dead space was calculated by use of Bohr's equation (8). Pulse rate was determined electrocardiographically and respiratory rate by means of a strain gauge assembly mounted on the expiratory side of an Otis-McKerrow twoway breathing valve.

The percentage of oxygen utilized by the tissues (expressed in terms of arterial oxygen content) was calculated as follows :

per cent oxygen utilized

$$
=\frac{\mathrm{AVO}_{2} \text { difference, } \mathrm{ml} \text { per } \mathrm{L}}{\text { arterial oxygen content, } \mathrm{ml} \text { per } \mathrm{L}} \times 100 .
$$

The oxygen transport to the tissues was expressed as follows : $\mathrm{O}_{2}$, transport $(\mathrm{ml}$ per minute $)=$ cardiac output ( $\mathrm{L}$ per minute) $\times$ arterial $\mathrm{O}_{2}$ content $(\mathrm{ml}$ per $\mathrm{L})$.

The alveolar-arterial (A-a) gradients for oxygen were determined using the alveolar air equation for alveolar $\mathrm{pO}_{2}$. The directly measured (polarographic) value for arterial $\mathrm{pO}_{2}$ was then subtracted from the calculated alveolar $\mathrm{pO}_{2}$.

It was not possible to achieve maximal levels of oxygen intake in the two patients with pernicious anemia, owing to peripheral neurological changes. Studies on these individuals were done at the maximal grade and speed tolerable to them.

In the remaining subjects, exercise trials were performed on the day prior to the complete experiment. With one exception, they were able to perform at a level of exercise sufficient to meet the criteria previously laid down as defining maximal oxygen intake (2). The 
TABLE I

Characteristics of anemic subjects

\begin{tabular}{|c|c|c|c|c|c|c|}
\hline \multirow[b]{2}{*}{ Subject } & \multirow[b]{2}{*}{ Age } & \multirow[b]{2}{*}{ Weight } & \multirow[b]{2}{*}{ Diagnosis } & \multirow[b]{2}{*}{ Hemoglobin } & \multicolumn{2}{|c|}{ Level of exercise* } \\
\hline & & & & & Speed & Grade \\
\hline & yrs & kg & & $g$ & miles/hr & $\%$ \\
\hline C. I. & 19 & 49.4 & Sickle cell anemia & 7.0 & 6 & 12.50 \\
\hline L. C. & 28 & 74.2 & Sickle cell anemia & 8.1 & 7 & 14.75 \\
\hline E. $R$. & 17 & 55.2 & Sickle cell anemia & 6.6 & 6 & 14.50 \\
\hline H. M. & 22 & 56.2 & Sickle cell $\mathrm{Hb} \mathrm{C}$ disease & 9.3 & 6 & 12.50 \\
\hline W. R. & 25 & 68.0 & Fe deficiency anemia (ulcer) & 8.0 & 7 & 14.75 \\
\hline & 23 & 68.1 & Fe deficiency anemia (nosebleeds) & 7.6 & 6 & 14.75 \\
\hline & 62 & 91.1 & Fe deficiency anemia (hemorrhoids) & 6.5 & 5 & 7.50 \\
\hline L. $\dot{M}$. & 54 & 66.6 & Pernicious anemia & 5.2 & 4 & 5.0 \\
\hline B. H. & 65 & 64.0 & Pernicious anemia & 6.3 & 3 & 5.0 \\
\hline
\end{tabular}

* Average level of exertion at which our normal subjects reached maximal oxygen intake was 6 miles per hour at a 12.5 per cent grade.

exception was a 62 year old, severely hypertensive man who weighed 270 pounds (Subject no. 7, L.J.).

Attempts to study patients after correction of their anemic state have not as yet been successful. Comparisons have therefore been made between anemic subjects and a large group of normal individuals who were evaluated previously by the same techniques $(2,9)$.

\section{RESULTS}

The means and standard deviations of the various parameters studied, both in the anemic pa- tients and in the normal subjects, while standing at rest and also during vigorous exercise, are shown in Tables II and III.

Blood samples were drawn during more than one period of severe exercise from some of the subjects, and therefore the number of determinations appearing in Table III under "exercise" is often greater than the number recorded during "standing rest."

The relationships of oxygen saturation and oxy-

TABLE II

Indexes of ventilation and blood flow at rest and during exercise in normal and anemic subjects

\begin{tabular}{|c|c|c|c|c|c|c|c|c|c|c|c|c|}
\hline & \multicolumn{7}{|c|}{ Standing rest } & \multicolumn{5}{|c|}{ Exercise } \\
\hline & \multicolumn{4}{|c|}{ Anemic } & \multicolumn{3}{|c|}{ Normal } & \multicolumn{3}{|c|}{ Anemic } & \multicolumn{2}{|l|}{ Normal } \\
\hline & \multicolumn{3}{|c|}{ Mean } & \multirow[t]{2}{*}{ No. } & \multicolumn{2}{|c|}{ Mean } & \multirow[t]{2}{*}{ No. } & \multicolumn{2}{|c|}{ Mean } & \multirow[t]{2}{*}{ No. } & Mean & \multirow[t]{2}{*}{ No. } \\
\hline Ventilatory function & & & & & & & & & & & & \\
\hline Ventilatiory $(\mathrm{L} / \mathrm{min})$ & 13.19 & \pm & $3.36 *$ & 9 & $10.15 \pm$ & 2.07 & 40 & $71.50 \pm$ & 21.0 & 9 & $73.50 \pm 10.43$ & 54 \\
\hline Respiratory rate (per min) & 18.5 & \pm & $2.3 *$ & 9 & $13.4 \pm$ & 3.8 & 36 & $40.1 \pm$ & $12.0^{*}$ & 9 & $23.1 \pm 13.0$ & 14 \\
\hline Tidal volume $(\mathrm{L})$ & 0.71 & \pm & 0.15 & 9 & $0.76 \pm$ & 0.12 & 36 & $1.85 \pm$ & $0.39 *$ & 9 & $3.18 \pm 0.42$ & 14 \\
\hline$V_{d}(L)$ & 0.27 & \pm & 0.13 & 7 & $0.20 \pm$ & 0.06 & 13 & $0.53 \pm$ & 0.19 & 9 & $0.45 \pm 0.10$ & 14 \\
\hline Alveolar ventilation $(\mathrm{L} / \mathrm{min})$ & 6.5 & $\overline{ \pm}$ & 3.4 & 9 & $7.5 \pm$ & 2.8 & 13 & $51.4 \pm$ & 21.3 & 9 & $62.8 \pm 18.4$ & 14 \\
\hline \multicolumn{13}{|l|}{ Blood flow function } \\
\hline Cardiac output ( $\mathrm{L} / \mathrm{min}$ ) & 8.6 & \pm & $2.2 *$ & 9 & $5.5 \pm$ & 0.9 & 15 & $23.6 \pm$ & 4.2 & 9 & $23.4 \pm 5.5$ & 15 \\
\hline Stroke volume $(c c)$ & 93 & \pm 2 & $21 *$ & 7 & 62 & & 13 & 118 & 22 & 9 & \pm 25 & 13 \\
\hline Pulse rate (per min) & 87 & \pm & & 7 & 91 & & 14 & 170 & 17 & 9 & \pm 10 & 13 \\
\hline Central volume $(L)$ & 2.00 & \pm & 0.61 & 9 & $1.71 \pm$ & 0.34 & 14 & $3.25 \pm$ & 0.71 & 9 & $3.49 \pm 0.83$ & 15 \\
\hline Appearance time (sec) & 8.3 & \pm & $2.1^{*}$ & 8 & $11.9 \pm$ & 2.2 & 14 & $5.4 \pm$ & 1.6 & 9 & $\cdot 5.9 \pm 1.3$ & 15 \\
\hline Mean circulation time (sec) & 14.1 & $\overline{ \pm}$ & $3.2 *$ & 9 & $18.5 \pm$ & 3.1 & 14 & $8.6 \pm$ & 1.8 & 9 & $9.4 \pm 2.0$ & 15 \\
\hline $\mathrm{AVO}_{2}$ difference (vol \%) & 4.1 & \pm & $1.6^{*}$ & 9 & $6.0 \pm$ & 0.9 & 11 & $8.8 \pm$ & $1.1 *$ & 9 & $14.3 \pm 2.5$ & 15 \\
\hline \multicolumn{13}{|l|}{ Gas exchange/metabolic activity } \\
\hline Oxygen intake $(\mathrm{L} / \mathrm{min})$ & 0.32 & \pm & 0.05 & 9 & $0.33 \pm$ & 0.05 & 11 & $1.84 \pm$ & 0.62 & 9 & $3.22 \pm 0.46$ & 15 \\
\hline $\mathrm{CO}_{2}$ output $(\mathrm{L} / \mathrm{min})$ & 0.22 & \pm & 0.06 & 9 & $0.25 \pm$ & 0.07 & 11 & $1.80 \pm$ & $0.49 *$ & 9 & $3.38 \pm 0.52$ & 15 \\
\hline R.Q. & 0.72 & \pm & 0.04 & 9 & $0.74 \pm$ & 0.06 & 11 & $1.03 \pm$ & 0.02 & 9 & $1.05 \pm 0.03$ & 15 \\
\hline $\begin{array}{l}\mathrm{O}_{2} \text { removal rate }(\mathrm{cc} / \mathrm{L}) \\
\mathrm{O}_{2} \text { transport to body tissues }\end{array}$ & 25.8 & \pm & 7.6 & 9 & $33.5 \pm$ & 8.3 & 11 & $25.9 \pm$ & $4.3^{*}$ & 9 & $43.3 \pm 4.2$ & 15 \\
\hline$(\mathrm{L} / \mathrm{min})$ & 0.84 & \pm & 0.17 & 9 & $0.98 \pm$ & 0.20 & 11 & $2.41 \pm$ & $0.37 *$ & 9 & $4.51 \pm 0.53$ & 15 \\
\hline $\mathrm{O}_{2}$ utilized, $\%$ & 41.6 & \pm & 6.8 & 9 & $38.5 \pm$ & 8.2 & 11 & $86.6 \pm$ & $9.3 *$ & 9 & $74.0 \pm 11.6$ & 15 \\
\hline
\end{tabular}

* Determinations which vary significantly from those in normals, $\mathrm{p}<0.05$. 
TABLE III

Blood gas and pH measurements at rest and during exercise in normal and anemic subjects

\begin{tabular}{|c|c|c|c|c|c|c|c|c|c|c|c|c|c|}
\hline \multirow[b]{3}{*}{ Site } & & \multicolumn{6}{|c|}{ Standing rest } & \multicolumn{6}{|c|}{ Exercise } \\
\hline & & \multicolumn{3}{|c|}{ Anemic } & \multicolumn{3}{|c|}{ Normal } & \multicolumn{3}{|c|}{ Anemic } & \multicolumn{3}{|c|}{ Normal } \\
\hline & & \multicolumn{2}{|c|}{ Mean } & \multirow{2}{*}{$\frac{\text { No. }}{7}$} & \multicolumn{2}{|c|}{ Mean } & \multirow{2}{*}{$\frac{\text { No. }}{11}$} & \multicolumn{2}{|c|}{ Mean } & \multirow{2}{*}{$\begin{array}{c}\text { No. } \\
9\end{array}$} & \multicolumn{2}{|c|}{ Mean } & \multirow{2}{*}{ No. } \\
\hline Brachial & A-a gradient $(\mathrm{mm} \mathrm{Hg})$ & 39.7 & \pm 11.0 & & 13.0 & \pm 6.5 & & 40.4 & \pm 17.0 & & 22.0 & \pm 8.2 & \\
\hline artery & $\mathrm{O}_{2}$ content ( vol $\left.\%\right)$ & 9.77 & \pm 1.61 & 9 & 18.41 & \pm 1.62 & 33 & 10.18 & \pm 1.92 & 16 & 19.62 & \pm 2.04 & 31 \\
\hline & $\mathrm{O}_{2}$ capacity (vol \%) & 11.24 & \pm 1.90 & 9 & 19.42 & \pm 1.73 & 33 & 11.86 & \pm 2.03 & 16 & 21.33 & \pm 1.81 & 31 \\
\hline & Saturation, $\%$ & 89.8 & \pm 8.5 & 9 & 94.9 & \pm 2.6 & 33 & 88.5 & \pm 8.2 & 16 & 93.4 & \pm 5.2 & 31 \\
\hline & Calc. $\mathrm{O}_{2}$ tension $(\mathrm{mm} \mathrm{Hg})$ & 68.4 & \pm 15.1 & 9 & 80.0 & \pm 7.5 & 33 & 73.5 & \pm 23.5 & 16 & 82.1 & \pm 12.6 & 31 \\
\hline & $\mathrm{O}_{2}$ tension $(\mathrm{mm} \mathrm{Hg})$ & 76.8 & \pm 15.5 & 9 & 85.0 & \pm 13.1 & 32 & 73.2 & \pm 11.3 & 16 & 86.0 & \pm 14.1 & 34 \\
\hline & $\mathrm{CO}_{2}$ content $(\mathrm{mEq} / \mathrm{L})$ & 20.2 & \pm 2.5 & $i$ & 24.0 & \pm 1.4 & 27 & 16.3 & \pm 2.7 & 15 & 20.4 & \pm 2.1 & 25 \\
\hline & $\mathrm{CO}$ tension $(\mathrm{mm} \mathrm{Hg})$ & 34.8 & \pm 5.1 & 7 & 39.0 & \pm 4.0 & 26 & 34.5 & \pm 5.1 & 15 & 40.0 & \pm 6.0 & 23 \\
\hline & $\mathrm{pH}$ & 7.41 & \pm 0.09 & 9 & 7.39 & \pm 0.04 & 36 & 7.32 & \pm 0.07 & 16 & 7.28 & \pm 0.05 & 32 \\
\hline \multirow{7}{*}{$\begin{array}{c}\text { Brachial } \\
\text { vein }\end{array}$} & $\mathrm{O}_{2}$ content $(\mathrm{vol} \%)$ & 3.50 & \pm 0.92 & 9 & 10.36 & \pm 1.71 & 25 & 2.44 & \pm 1.80 & 11 & 5.18 & \pm 1.10 & 19 \\
\hline & Saturation, $\%$ & 33.4 & \pm 12.3 & 9 & 55.0 & \pm 15.0 & 25 & 20.6 & \pm 13.1 & 11 & 25.0 & \pm 9.8 & 19 \\
\hline & Calc. $\mathrm{O}_{2}$ tension $(\mathrm{mm} \mathrm{Hg})$ & 20.2 & \pm 4.5 & 9 & 30.2 & \pm 6.1 & 25 & 16.2 & \pm 9.9 & 11 & 19.3 & \pm 8.4 & 19 \\
\hline & $\mathrm{O}_{2}$ tension $(\mathrm{mm} \mathrm{Hg})$ & 32.7 & \pm 10.3 & 9 & 29.1 & \pm 8.0 & 22 & 30.1 & \pm 4.9 & 12 & 24.2 & \pm 8.0 & 18 \\
\hline & $\mathrm{CO}_{2}$ content $(\mathrm{mEq} / \mathrm{L})$ & 23.7 & \pm 1.7 & 9 & 26.1 & \pm 2.2 & 20 & 20.7 & \pm 2.8 & 10 & 26.9 & \pm 2.2 & 15 \\
\hline & $\mathrm{CO}_{2}$ tension $(\mathrm{mm} \mathrm{Hg})$ & 49.6 & \pm 6.9 & $i$ & 45.0 & \pm 5.2 & 20 & 54.8 & \pm 6.8 & 10 & 71.0 & \pm 13.2 & 15 \\
\hline & $\mathrm{pH}$ & 7.34 & \pm 0.08 & 9 & 7.36 & \pm 0.04 & 25 & 7.21 & \pm 0.05 & 12 & 7.21 & \pm 0.12 & 22 \\
\hline \multirow{7}{*}{$\begin{array}{c}\text { Femoral } \\
\text { vein }\end{array}$} & $\mathrm{O}_{2}$ content ( vol $\left.\%\right)$ & 3.10 & \pm 1.20 & 9 & 7.72 & \pm 2.31 & $2 \pi$ & 1.35 & \pm 1.03 & 14 & 6.88 & \pm 3.11 & 20 \\
\hline & Saturation, $\%$ & 29.2 & \pm 11.8 & 9 & 40.2 & \pm 14.4 & 27 & 11.7 & \pm 7.6 & 14 & 27.6 & \pm 2.2 & 20 \\
\hline & Calc. $\mathrm{O}_{2}$ tension $(\mathrm{mm} \mathrm{Hg})$ & 19.3 & \pm 1.8 & 9 & 24.2 & \pm 7.0 & 27 & 10.6 & \pm 6.1 & 14 & 22.1 & \pm 7.3 & 20 \\
\hline & $\mathrm{O}_{2}$ tension $(\mathrm{mm} \mathrm{Hg})$ & 35.5 & \pm 12.1 & 9 & 26.3 & \pm 10.3 & 25 & 23.4 & \pm 7.1 & 14 & 25.0 & \pm 9.0 & 24 \\
\hline & $\mathrm{CO}_{2}$ content $(\mathrm{mEq} / \mathrm{L})$ & 22.2 & \pm 2.2 & 9 & 26.9 & \pm 2.3 & 24 & 22.1 & \pm 2.31 & 14 & 27.6 & \pm 2.2 & 20 \\
\hline & $\mathrm{CO}_{2}$ tension $(\mathrm{mm} \mathrm{Hg})$ & 50.6 & \pm 3.5 & $i$ & 47.1 & \pm 6.0 & 24 & 60.6 & \pm 8.3 & 14 & 83.0 & \pm 11.2 & 21 \\
\hline & $\mathrm{pH}$ & 7.31 & \pm 0.12 & 9 & 7.35 & \pm 0.05 & 29 & 7.21 & \pm 0.04 & 14 & 7.13 & \pm 0.08 & 28 \\
\hline
\end{tabular}

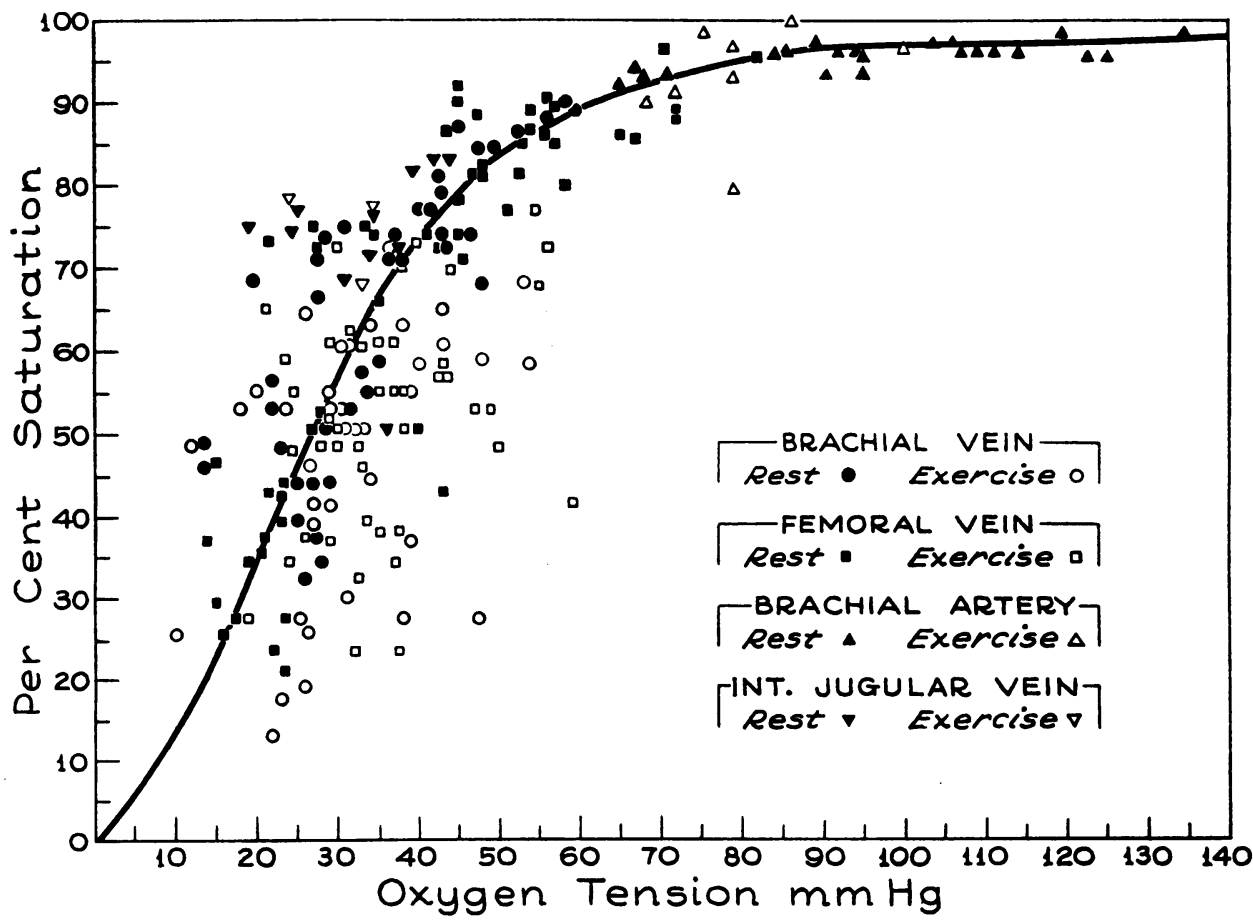

Fig. 1. Normal subjects at Rest and during exercise. 
gen tension (both of which have been corrected to $\mathrm{pH} 7.40)(10)$ are shown plotted with respect to standard oxygen dissociation curves (11) in Figure 1 for normal subjects and in Figure 2 for anemic patients.

The relationships between $\mathrm{CO}_{2}$ content, $\mathrm{CO}_{2}$ tension and $\mathrm{pH}$ are graphically depicted in Figure 3. The venous values for each of these parameters were obtained by summing the values obtained from the femoral and brachial veins and dividing by two.

In order to stress certain findings pertinent to the subsequent discussion, the more important results are summarized in the following paragraphs.

At rest. Ventilatory volume tended to be larger, and respiratory rate faster, than normal in the anemic individuals at rest (Table II). There was no significant difference in tidal volume, physiological dead space, or alveolar ventilation between normal and anemic subjects.

Resting cardiac output and stroke volume were larger than normal. Pulse rate, however, was not increased at rest.

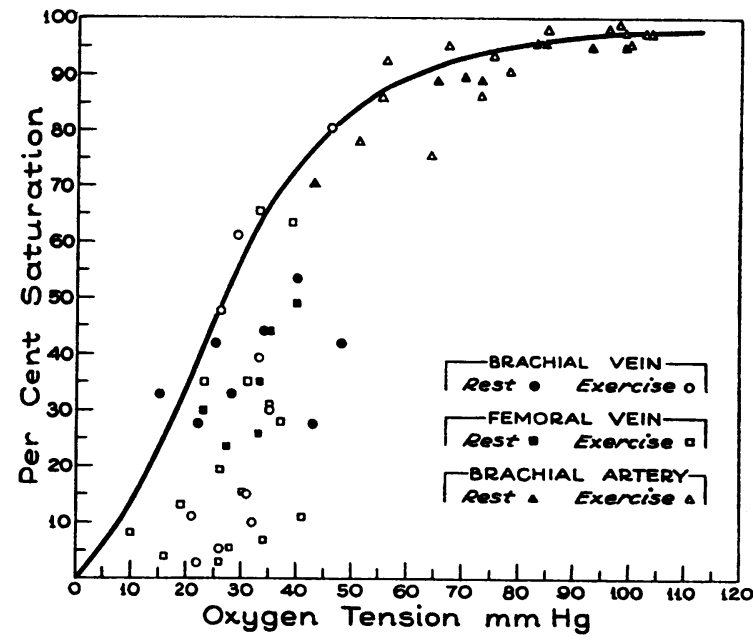

Fig. 2. NORMaL $\mathrm{O}_{2}$ DISSOciation CURVE FOR $\mathbf{P H} \mathbf{7 . 4 0}$ COMPARED WITH CORRECTED VALUES OBTAINED IN ANEMIC PATIENTS.

Gas exchange and metabolic activity, as indicated by oxygen intake, $\mathrm{CO}_{2}$ output, total oxygen transport to and the percentage of oxygen utilized by the body tissues, were similar in resting anemic and in resting normal subjects.

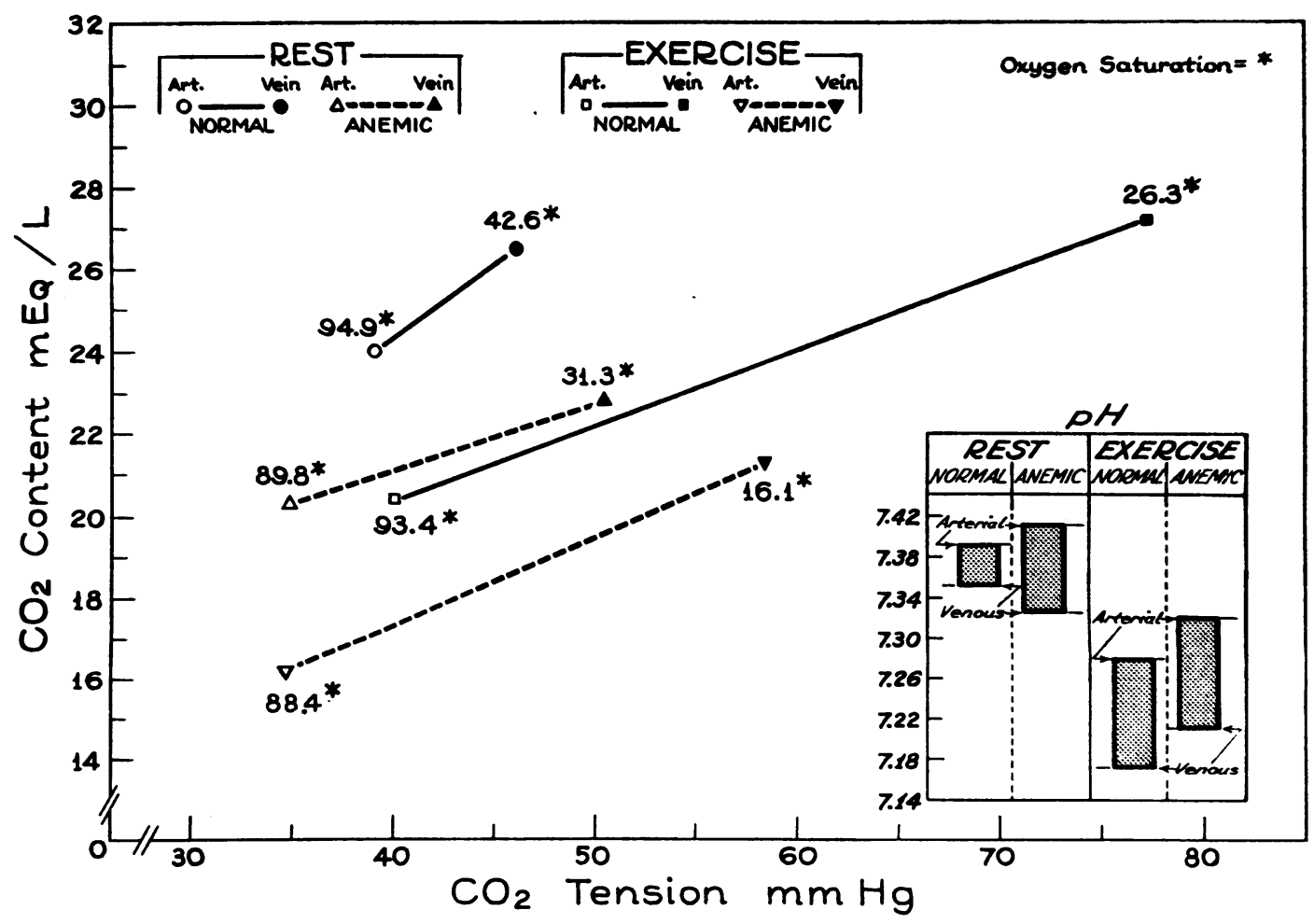

Fig. 3. Arterial and venous $\mathrm{CO}_{2}$ tension and $\mathrm{CO}$ : content at rest and during exercise. 
The A-a gradient for oxygen tended to be increased in the anemic subjects at rest (Table III). A shift to the right of the oxygen dissociation curve was indicated (Table III and Figure 2) by directly measured oxygen tensions which tended to be higher than oxygen tensions calculated from the Van Slyke values and $\mathrm{pH}$ by use of the normal oxygen dissociation curves of Dill (11).

Although arterial and venous carbon dioxide content, as well as $\mathrm{CO}_{2}$ tension (Table III and Figure 3) were lower in anemic than in normal subjects, the arteriovenous (A-V) $\mathrm{CO}_{2}$ content difference was the same, while the $\mathrm{A}-\mathrm{V} \mathrm{CO} \mathrm{CO}_{2}$ tension difference was greater than normal. This was reflected by a wider $\mathrm{A}-\mathrm{V} \mathrm{pH}$ difference in anemic subjects at rest (Figure 3 insert).

During exercise. Equivalent grades of exercise resulted in similar levels of minute ventilation in normal and anemic subjects (Table II). However, the anemic individuals moved a smaller tidal volume at a faster respiratory rate and the physiological dead space increased relative to tidal volume much more in violently exercising anemic patients than in normal subjects. Alveolar ventilation was therefore less in the exercising anemic than in exercising normal subjects.

Cardiac output, stroke volume, pulse rate, central blood volume and mean circulation time during heavy exercise were approximately the same in anemic patients as in normal subjects.

Although the peripheral tissues of the anemic subjects utilized a higher percentage of the oxygen transported by hemoglobin during severe exercise, a markedly decreased oxygen-carrying capacity limited the possibility of expanding the $\mathrm{AVO}_{2}$ difference. The oxygen removal rates per liter of ventilation, as well as the total oxygen intake per minute, were therefore found to be significantly less in anemic than in normal subjects at similar levels of exercise (Table II). The $\mathrm{CO}_{2}$ production of the anemic individuals was similarly depressed relative to normal.

During strenuous exertion of anemic patients, the values for $\mathrm{A}-\mathrm{a} \mathrm{O}_{2}$ gradient, arterial $\mathrm{pO}_{2}$ and oxygen saturation were not significantly different from those observed at rest. Oxygen tension measured directly in venous blood, again as at rest, was significantly higher than was oxygen tension calculated from per cent saturation and $\mathrm{pH}$ using standard $\mathrm{O}_{2}$ dissociation curves (Figure 2).
The $\mathrm{CO}_{2}$ content and $\mathrm{CO}_{2}$ tension of both arterial and venous blood, as at rest, were less than normal in subjects with anemia during intense exertion (Figure 3 ). In contrast to the situation at rest, the $\mathrm{A}-\mathrm{V} \mathrm{CO} \mathrm{CO}_{2}$ content and tension differences were less in exercising anemic than in exercising normal subjects. The $\mathrm{A}-\mathrm{V} \mathrm{pH}$ difference was similar in the two groups of exercising subjects, although the absolute level of $\mathrm{pH}$ was higher in both the arterial and venous blood of the exercising anemic individuals.

\section{DISCUSSION}

It is apparent that by expanding available hemodynamic compensatory mechanisms, the anemic individual at rest is able to handle the delivery of oxygen and the transport of $\mathrm{CO}_{2}$ in relatively adequate fashion.

During vigorous exercise, however, despite what must be presumed to be maximal utilization of all available hemodynamic adjustments, the supply of oxygen to working cells is sharply limited and the production of $\mathrm{CO}_{2}$ is also curtailed. It was surprising that such high levels of exercise could be achieved without obvious symptomatic distress, since, in the tissues, one would suppose that a large oxygen debt must necessarily be incurred.

This study suggests that although the anemic state itself may, to a slight extent, alter the ability of the cardiopulmonary apparatus to respond to stress, the predominant limitation upon the exercising anemic individual is imposed by an abnormally decreased quantity of available hemoglobin.

Ventilation. Despite the larger minute ventilation of the anemic patients, the resting alveolar ventilation of normal subjects and anemic patients was similar. This can be accounted for by the fact that the increase in total ventilation was accomplished entirely by an increase in respiratory rate. Interestingly enough, the marked increase in respiratory rate during vigorous exercise in anemic patients was not accompanied by greater total ventilation than that observed in normal subjects.

The factor or factors triggering the increase in respiratory rate are unclear, but possibilities are that the mechanical properties of the lung may be altered, or that an alteration in the composition of the blood bathing the respiratory center might mediate the increase. 
An investigation by McIlroy, Eldridge and Stone (12) of the mechanical properties of the lungs in several patients with anemia during only mild exercise was considered to demonstrate no apparent abnormalities. These studies would appear to exclude mechanical factors as a possible mechanism for the rate alteration; however, a more extensive investigation of mechanical function including heavier exercise might throw additional light on this problem.

Whatever the reason for the alteration of the respiratory rate tidal volume relationship, there can be no question but that the observed increase in respiratory rate reflects a greatly increased work of breathing in the anemic subject as compared with that of normal subjects. Despite this relative increase in the work of breathing, the subjective appreciation of dyspnea was apparently no greater than that seen in normal individuals exercising at the same levels.

It is important to note that during exercise the alveolar ventilation of the anemic subjects relative to the quantity of carbon dioxide which they were releasing to the lungs was increased over normal. Therefore, despite calculated minute alveolar ventilations which were the same or smaller than normal, the anemic subjects were, in a more fundamental sense, hyperventilating. This situation was mirrored by the lower-than-normal $\mathrm{CO}_{2}$ tensions measured in anemic arterial blood.

Blood flow. The current studies confirm the well documented fact that the cardiac output of anemic subjects at rest is increased over normal (13). Total blood volume was not measured in the present group of experimental subjects. However, in another group of patients with sickle cell disease, total blood volume as measured by dye and radioactive chromuim dilution methods was found to be increased (14). This is at variance with the impression of most workers that total blood volume is decreased in the presence of anemia (15). However, much of the experimental work on anemia has been done on animals made anemic by hemorrhage and such preparations might be expected to have a diminished total blood volume. In the present study, using the method of Hamilton and associates ( 7 ), the "central" blood volume of anemic patients was increased as compared with that found in normal subjects.

In both normal and anemic subjects there was a marked increase in "central" blood volume from rest to exercise. The magnitude of these increases is difficult to reconcile with observations that the diastolic size of the heart decreases during exercise (16) and with the studies of Asmussen, Christensen and Sjöstrand (17) which showed no change in lung volume during maximal exercise. Since the pulmonary blood volume is a very small proportion of the "central" blood volume such discrepancies are not too surprising.

The studies of Bishop, Donald and Wade (1) led them to believe that the hyperkinetic response, once established, is present at all levels of activity and that an individual with an increased output at rest would maintain this increased flow over normal through all grades of exercise. This may be true until a level of activity is reached somewhere near that producing maximal oxygen intake; beyond such levels, cardiac output either levels off or declines (2). At this level of exertion, the cardiac response of normal and anemic subjects is apparently equivalent. Such equivalence is surprising since one might assume, a priori, that because a myocardial reserve is already encroached upon at rest, the myocardial muscle of an anemic individual would be less able to respond to severe stress than would a normal myocardium.

It is possible that during exercise, coronary blood flow in animals may be significantly augmented owing to a decrease in the viscosity of arterial blood. Studies performed on dogs made acutely anemic by Case, Berglund and Sarnoff (18) indicated that coronary flow in the anemic dogs was increased because of lower coronary resistance. This same study showed that the ventricular function curves of these open-chest, narcotized dogs were not depressed until the hematocrit had been reduced to between 24 and 31 per cent, a level of hematocrit below which most of our anemic subjects did not fall. It is apparent that, since the coronary sinus blood is extremely desaturated even in the normal individual at rest (19), oxygen delivery to the anemic myocardium must be augmented, during exercise, almost entirely by increase in blood flow.

It is noteworthy that both normal and anemic subjects demonstrated a marked increase in stroke volume from rest to strenuous exercise. The anemic individuals had a larger stroke volume than normal at rest and while a further increase 
was obtained during exercise, it was only such as to make the normal and the anemic stroke volumes comparable. Since rate was comparable under all circumstances, changes in stroke volume generally reflected changes in cardiac output. These findings are in contrast to Rushmer and Smith's observations suggesting that stroke volume usually does not change during exercise (20). It may be that some of the discrepancy is explicable by the fact that, in our studies, both resting and exercise values were obtained in the upright position. In this posture, stroke volume tends to be less than it is in the supine position (21) and is therefore more subject to increase under the impact of added stress. Some of the observations on which Rushmer and Smith based their reasoning were from studies done in the supine position and many were made at lower levels of exercise than those used by us. Rushmer's own very ingenious experiments, of course, were all performed on dogs.

Blood gas exchange. Previous studies from this laboratory in normal subjects $(2,9)$ indicated that although the oxygen dissociation characteristics of hemoglobin were normal at rest, there was a shift to the right of the dissociation curve, particularly in venous blood, during heavy exercise (see Figure 1). In the venous blood of anemic subjects. this phenomenon appears to be present not only during violent exercise, where it is perhaps more pronounced than in normal subjects, but also at rest. Kennedy and Valtis (22) cite evidence that the dissociation curve of anemic blood, studied in vitro, is shifted to the right and that it tends to revert to normal upon correction of the anemic state. Such a phenomenon has been reported as measured in vivo in resting patients with sickle cell anemia by Rodman and associates (23). In our patients the results suggest that the oxygen dissociation curve under the conditions of anemia and exercise is changed in shape so that the lower portion of the curve is shifted to the right while the upper portion remains relatively normal.

A similar change, as illustrated in Figure 1, occurs in normal subjects during exercise but possibly the change is greater in anemia (Figure 2 ) and is also made more obvious by increased venous desaturation in the exercising anemic subjects. It seems possible that the changes shown in anemia might be but an extension of a normal exercise phenomenon, demonstrable because a lower portion of the oxygen dissociation curve is analyzed in the venous blood of the exercising anemic subject.

The factors eliciting these changes in dissociation characteristics in either normal people during exercise, or the more profound changes in anemic people both at rest and in exercise, have not been fully elucidated.

Gambino (24) has reported that, during exercise, the $\mathrm{pH}$ of plasma is $0.10 \mathrm{pH}$ unit higher than that of whole blood. It is probable that this difference might be exaggerated in anemic blood, and it may be that these observations reflect an intracorpuscular $\mathrm{pH}$ which is very significantly less than that measured on whole blood. Such a decrease, if great enough, could explain our findings.

At any rate, there can be little doubt that the change in dissociation characteristics of hemoglobin suggested by these data is theoretically helpful in maintaining an adequate oxygen gradient at the tissue level and in insuring the continued unloading of oxygen under conditions in which the hemoglobin is extremely unsaturated.

It seems obvious that A-a oxygen tension gradients in anemia are increased over normal both at rest and during exercise. As previously pointed out from data obtained on a larger group of subjects possessing the $\mathrm{S}$ type of hemoglobin, the increase in A-a gradient found in patients with sickle cell disease (14) is greater than that to be expected on the basis of anemia alone (25). More definitive studies with three levels of oxygen-breathing suggested that, in the sickle cell patients, the increased A-a gradient, when the patients were breathing room air, was principally related to intrapulmonary shunting, although distribution defects and diffusion defects also existed (14). In the present group of patients, the increase in A-a gradient at rest might be the result of shunting, ventilation blood flow disturbances or of defects in diffusion. Alveolar ventilation does not directly affect the A-a gradient and in any case (as reflected by the normal or low $\mathrm{CO}_{2}$ tensions) it was adequate in these subjects. During strenuous exercise, the abnormalities of oxygenation do not apparently change. since A-a gradients, although still elevated above normal, show no further increase. Such a lack of change on exercise militates against a diffusion defect's being predominant in causing the widening 
of the gradient at rest. One is therefore left with the impression that the defect in oxygenation of hemoglobin seen in anemia is probably related to a combination of change in dissociation characteristics plus an intrapulmonary disturbance in ventilation blood flow relationships.

Since the percentage of oxygen utilized by the peripheral tissues was not significantly greater than normal in the resting anemic subjects, it is apparent that, at rest, the decrease in $\mathrm{O}_{2}$-carrying capacity is adequately compensated for by increased blood flow. During heavy exercise, on the other hand, despite a slight increase in oxygen capacity and maximal widening of the $A-V$ oxygen difference, the delivery of oxygen by the anemic subject is seriously hampered by the reduced available hemoglobin. Despite the attainment of cardiac outputs comparable to those of normal individuals, oxygen intake is significantly depressed. It may be that the lack of anoxic symptoms, which might be expected to accompany such a very pronounced decrease in oxygen intake at high workloads, is partly attributable to the maintenance of tissue oxygen tension resulting from dislocation of the oxygen dissociation curve in anemic subjects. It is apparent that a greater-than-normal oxygen debt must be contracted during severe exercise by the anemic individual, but the cardiovascular system seems to adjust itself to short periods of extreme effort so that this debt can slowly be repaid without producing undue distress.

Carbon dioxide, Although most of the carbon dioxide given off by the tissues is carried by plasma rather than by the red blood cells, it is the erythrocyte which, largely through operation of the chloride shift, initiates and perpetuates the process of $\mathrm{CO}_{2}$ transport. It is not surprising, therefore, that in anemic subjects, both at rest and during exercise, the usual indexes of $\mathrm{CO}_{2}$ transport are distorted.

Characteristically (15), the flattening of the $\mathrm{CO}_{2}$ dissociation curve was usually reflected in these anemic subjects, at rest (Figure 3 ), by an elevated arteriovenous $\mathrm{CO}_{2}$ tension difference relative to the difference in the $\mathrm{CO}_{2}$ content between arterial and venous blood. The latter was comparable to that measured in our resting normal subjects. Also the arteriovenous $\mathrm{pH}$ difference, as is generally reported (15), was increased over normal in the anemic subjects and this increase was achieved by virtue of increased alkalinity (due to hyperventilation) of the arterial blood plus a more pronounced acidity of the venous blood.

A shift to the right of the $\mathrm{O}_{2}$ dissociation curve (Figure 2 and Table II) resulted in a situation in which the venous oxygen saturations of anemic subjects were very significantly lower than normal, despite normal resting venous oxygen tensions. The difference between arterial and venous oxygen saturation thus tends to be exaggerated and since reduced hemoglobin is a weaker acid than oxyhemoglobin, the buffer power of the smaller available quantity of hemoglobin is enhanced and $\mathrm{CO}_{2}$ transport is abetted. This effect, first pointed out by Christiansen, Douglas and Haldane (26), means that oxygenation of the blood has a more important effect on carbon dioxide transport than the converse effect of carbon dioxide on oxygen transport. At rest, this and other compensations occurring in anemia are capable of enhancing carbon dioxide transport sufficiently so that the same total $\mathrm{CO}_{2}$ output can be handled by resting normal and anemic subjects.

It is very difficult to quantitate the various mechanisms whereby the process of carbon dioxide transport, despite compensation, might be unduly taxed in anemia, and the ability of the blood to transport increased loads of carbon dioxide is exceeded. The importance of the decreased available quantity of carbonic anhydrase (itself attributable to the paucity of red cells) in hampering $\mathrm{CO}_{2}$ exchanges is not precisely known, particularly since these exchanges are not entirely dependent on the amount of $\mathrm{CO}_{2}$ carried directly in red blood cells. As secondary buffering of the plasma contributed by the chloride shift enhances the overall importance of the catalytic hydration of carbon dioxide, it is possible that depression of this mechanism by a reduced red cell mass might be paramount. Diminished formation of carbamino compounds associated with reduction in hemoglobin mass would probably be of secondary importance, since it has been calculated by Ferguson (27) that changes in carbamino-bound $\mathrm{CO}_{2}$ are responsible for only about 30 per cent of the total changes in $\mathrm{CO}_{2}$ in whole blood during the respiratory cycle.

It is obvious that the red cell mechanism for carrying carbon dioxide is not significantly exceeded in anemic people during strenuous exertion, 
in fact, the lower-than-normal $\mathrm{CO}_{2}$ tensions demonstrated in anemic venous blood suggests that, during severe exercise, the removal of carbon dioxide from the tissues may be performed more completely by anemic than by normal subjects. The total amount of carbon dioxide produced, however, is apparently very much less in the anemic people. The fact that the R.Q. of exercising normal and anemic subjects is the same indicates that an equal depression of oxygen and carbon dioxide transport occurs in severely exercising anemic individuals. By the same token, it may be taken to reflect the fact that $\mathrm{CO}_{2}$ production is coupled with oxygen consumption and therefore with aerobic metabolism.

The $\mathrm{A}-\mathrm{V} \mathrm{CO}$ tension difference of anemic subjects during severe exercise, while greater than that measured in resting anemic individuals, is much less than the difference recorded from normal exercising subjects. This is in contrast to the resting state in which the $\mathrm{A}-\mathrm{V} \mathrm{CO} \mathrm{CO}_{2}$ tension difference is much greater in anemic than in normal subjects. The narrowing of $\mathrm{A}-\mathrm{V} \mathrm{CO}_{2}$ tension difference in exercising anemic, as compared with exercising normal, subjects can be explained as the end result of three factors. First, there is slight narrowing of the exercising anemic $\mathrm{A}-\mathrm{V} \mathrm{CO} \mathrm{CO}_{2}$ content difference as compared to normal. Second, a lowering of the absolute levels of both the arterial and the venous $\mathrm{CO}_{2}$ tension of anemic as compared to normal individuals during severe exercise means that the anemic subject is operating on a lower and steeper portion of the anemic $\mathrm{CO}_{2}$ dissociation curve (15). Finally, the widening of the $\mathrm{A}-\mathrm{V}$ oxygen difference during exercise in anemia to the widest possible limits results in maximal utilization of the Haldane effect (26) by the exercising anemic subject. Since most of this narrowing of the $\mathrm{A}-\mathrm{V} \mathrm{CO} \mathrm{CO}_{2}$ tension difference is the result of a relative reduction in venous $\mathrm{CO}_{2}$ tension, the phenomenon is, basically, a reflection of diminished $\mathrm{CO}_{2}$ production and thus of reduced aerobic metabolism in anemia.

If $\mathrm{pH}$ reflected the partial pressure of $\mathrm{CO}_{2}$ only, one would expect the $\mathrm{A}-\mathrm{V} \mathrm{pH}$ difference to be smaller than normal in exercising anemic as opposed to exercising normal individuals. However, hydrogen ion concentration is determined by other factors, in addition to $\mathrm{pCO}_{2}$; and the inadequacy of the buffering power of anemic, as opposed to normal, blood was reflected during severe exercise by an $\mathrm{A}-\mathrm{V}$ pH difference which, despite the decreased $\mathrm{A}-\mathrm{V} \mathrm{pCO}_{2}$ difference, was similar to that found in normal subjects. The degree of acidity produced, however, in the venous and secondarily in the arterial blood of the anemic subjects by violent exertion was not nearly so profound as that encountered in normal people exercising at the same levels. Some of this difference might be explained by an increased oxylabile ionization of the more desaturated anemic hemoglobin, since such increased ionization appreciably enhances the ability of hemoglobin to buffer acids (28). However, it seems unlikely that such a mechanism could actually overcompensate for the reduced buffering capacity associated with the decreased hemoglobin mass. A comparable quantity of the acid production should still result in equal if not in greater hydrogen ion concentrations in the blood of anemic as compared with normal subjects.

Since the total quantity of acid produced during exercise represents the sum of the end product of aerobic metabolism (carbon dioxide) and of anaerobic metabolism (lactic acid and similar substances), the anemic individual, with his greatly diminished $\mathrm{CO}_{2}$ production, must have a relative increase in anaerobic metabolism. Since the two groups of subjects were exercising at similar grades and speeds on the treadmill one would assume that their energy expenditure would also be very similar; the anemic subjects, if anything, expending more effort as work of breathing. Total metabolism, in turn, should be related to total energy expenditure and should be similar in the two groups of subjects. Although, as Huckabee (29) suggests, lactic acid alone is not necessarily a linear index of the degree of anaerobic metabolism, one would imagine that any combination of lactate and pyruvate plus other metabolites stemming from an anaerobic process would act to increase the hydrogen ion concentration. Assuming that immediate blood measurements reflect this change, the results obtained in this study would suggest that the anemic individual's buffering mechanisms, temporarily at least, may be significantly augmented during exercise or that the end products of anaerobic metabolism are not so effective in lowering the $\mathrm{pH}$ as is carbon dioxide.

It may be, of course, that the end products of either aerobic metabolism, anaerobic metabolism or 
of both are temporarily sequestered and, if measured in the blood stream during the recovery phase following exercise, could be more logically correlated with the metabolic processes occurring during severe exertion.

\section{SUM MARY}

The cardiopulmonary responses of nine male patients with various types of anemia were compared with those of a larger number of normal subjects during heavy treadmill exercise.

At rest, anemic individuals, by expanding available hemodynamic compensatory mechanisms, are able to handle the delivery of oxygen and transport of $\mathrm{CO}_{2}$ in relatively adequate fashion. Compensation was achieved by several means which included an increased level of ventilation and cardiac output, a shift to the right of the oxygen dissociation curve, and an increased desaturation of venous blood which, because of the Haldane effect, augmented carbon dioxide transport.

During strenuous exercise, these hemodynamic adjustments were insufficient to prevent a marked depression of both oxygen intake and carbon dioxide production in comparison with those found in normal individuals exercising at comparable levels. Despite the evidence for an increase in anaerobic metabolism in anemic subjects, and in spite of the reduced buffering capacity reflected in the resting state by an increased $\mathrm{A}-\mathrm{V} \mathrm{pH}$ difference, the arterial and venous $\mathrm{pH}$ was not lower than normal. The absence of a greatly exaggerated arteriovenous $\mathrm{pH}$ difference during vigorous exercise suggests that there may be a lag in the release from the tissues of acid metabolites arising from anaerobic glycolysis in anemic patients. Nevertheless, they evidenced no more symptomatic distress than did normal people during these same periods of violent exercise.

\section{ACKNOWLEDGMENT}

The authors wish to express their appreciation to $\mathrm{Mr}$. Bernard Williams and Mrs. Tommie Kemp for valuable technical assistance.

\section{REFERENCES}

1. Bishop, J. M., Donald, K. W., and Wade, O. L. Circulatory dynamics at rest and on exercise in the hyperkinetic states. Clin. Sci. 1955, 14, 329.
2. Mitchell, J. H., Sproule, B. J., and Chapman, C. B. The physiological meaning of the maximal oxygen intake test. J. clin. Invest. 1958, 37, 538.

3. Singer, R. B., and Hastings, A. B. An improved clinical method for the estimation of disturbances of acid-base balance of human blood. Medicine (Baltimore) 1948, 27, 223.

4. Sproule, B. J., Miller, W. F., Cushing, I. E., and Chapman, C. B. An improved polarographic method for measuring oxygen tension in whole blood. J. appl. Physiol. 1957, 11, 365.

5. Miller, W. F., Sproule, B. J., and Cushing, I. E. A study of the nature of arterial oxygen lack using an improved rapid method of measuring oxygen tension. Amer. Rev. Tuberc. 1959, 79, 315.

6. Riley, R. L., Campbell, E. J. M., and Shepard, R. H. A bubble method for estimation of $\mathrm{pCO}_{2}$ and $\mathrm{pO}_{2}$ in whole blood. School of Aviation Medicine Research Reports, 58-135, Nov. 1958.

7. Hamilton, W. F., Moore, J. W., Kinsman, J. M., and Spurling, R. G. Studies on the circulation. IV. Further analysis of the injection method, and of changes in hemodynamics under physiological and pathological conditions. Amer. J. Physiol. 1932, 99, 534.

8. Comroe, J. H., Jr., Forster, R. E., II, DuBois, A. B., Briscoe, W. A., and Carlson, E. The Lung. Chicago, Year Book Publishers, Inc., 1955, p. 81.

9. Mitchell, J. H., Sproule, B. J., and Chapman, C. B. Factors influencing respiration during heavy exercise. J. clin. Invest. 1958, 37, 1693.

10. Severinghaus, J. W. Oxyhemoglobin dissociation curve correction for temperature and $\mathrm{pH}$ variation in human blood. J. appl. Physiol. 1958, 12, 485.

11. Consolazio, C. F., Johnson, R. E., and Marek, E. Metabolic Methods. Clinical Procedures in the Study of Metabolic Functions. St. Louis, C. V. Mosby Co., 1951, p. 309.

12. McIlroy, M. B., Eldridge, F. L., and Stone, R. W. The mechanical properties of the lungs in anoxia, anaemia, and thyrotoxicosis. Clin. Sci. 1956, 15, 353.

13. Brannon, E. S., Merrill, A. J., Warren, J. V., and Stead, E. A., Jr. The cardiac output in patients with chronic anemia as measured by the technique of right atrial catheterization. J. clin. Invest. 1945, 24, 332.

14. Sproule, B. J., Halden, E. R., and Miller, W. F. A study of cardiopulmonary alterations in patients with sickle cell disease and its variants. J. clin. Invest. 1958, 37, 486.

15. Blumgart, H. L., and Altschule, M. D. Clinical significance of cardiac and respiratory adjustments in chronic anemia. Blood 1948, 3, 329.

16. Chapman, C. B., Baker, O,, and Mitchell, J. H. Left ventricular function at rest and during exercise. J. clin. Invest. 1959, 38, 1202.

17. Asmussen, E., Christensen, E. H., and Sjöstrand, T. Uber die Abhängigkeit der Lungenvolumen von der 
Blutverteilung. Skand. Arch. Physiol. 1939, 82, 193.

18. Case, R. B., Berglund, E., and Sarnoff, S. J. Ventricular function. VII. Changes in coronary resistance and ventricular function resulting from acutely induced anemia and the effect thereon of coronary stenosis. Amer. J. Med. 1955, 18, 397.

19. Bing, R. J., Hammond, M. M., Handelsman, J. C., Powers, S. R., Spencer, F. C., Eckenhoff, J. E., Goodale, W. T., Hafkenschiel, J. H., and Kety, S. S. The measurement of coronary blood flow, oxygen consumption, and efficiency of the left ventricle in man. Amer. Heart J. 1949, 38, 1.

20. Rushmer, R. F., and Smith, O. A., Jr. Cardiac control. Physiol. Rev. 1959, 39, 41.

21. Stead, E. A., Jr., Warren, J. V., Merrill, A. J., and Brannon, E. S. The cardiac output in male subjects as measured by the technique of right atrial catheterization. Normal values with observations on the effect of anxiety and tilting. J. clin. Invest. 1945, 24, 326.

22. Kennedy, A. C., and Valtis, D. J. The oxygen dissociation curve in anemia of various types. J. clin. Invest. 1954, 33, 1372.
23. Rodman, T., Close, H. P., Fraimow, W., Cathcart, R., and Purcell, M. K. The oxygen dissociation curve in the common hemoglobinopathies (abstract). Clin. Res. 1958, 6, 189.

24. Gambino, S. R. The effect of exercise on the difference between the $\mathrm{pH}$ of plasma and whole blood. Clin. Res. 1958, 6, 409.

25. Ryan, J. M., and Hickam, J. B. The alveolar-arterial oxygen pressure gradient in anemia. J. clin. Invest. 1952, 31, 188.

26. Christiansen, J., Douglas, C. G., and Haldane, J. S. The absorption and dissociation of carbon dioxide by human blood. J. Physiol. (Lond.) 1914, 48, 244.

27. Ferguson, J. K. W. Carbamino compounds of $\mathrm{CO}_{2}$ with human haemoglobin and their role in the transport of $\mathrm{CO}_{2}$. J. Physiol. (Lond.) 1936, 88, 40.

28. Roughton, F. J. W. Respiratory functions of the blood in Handbook of Respiratory Physiology. Air University, USAF School of Aviation Medicine, September 1954, p. 85.

29. Huckabee, W. E. Relationships of pyruvate and lactate during anaerobic metabolism. II. Exercise and formation of $\mathrm{O}_{2}$-debt. J. clin. Invest. 1958, 37, 255. 